serious handicap to university students reading mathematics and science.

The report sets a target that 30 per cent of the active population (people between 20 and 63) should have a knowledge of Russian - thus giving Russian, for the first time, parity with German in importance as a means of international communication.

Language study in Finnish schools is complicated by the existence of two national languages - Finnish and Swedish - one of which has virtually no use and the other only limited use as a means of international communication.

According to the new proposals, all school-children must learn one foreign language (at present this is usually English) and the "other national language" (Swedish for Finnish-speakers and conversely). Study of a third language is optional, and introduced in the eighth class (15 plus).

According to the 1977 figures, some 0.2 per cent of school-children learn Russian as their first language and 6.2 per cent as their third language. The committee's recommendation of a 30 per cent Russianspeaking "active population" seems, therefore, an improvement. Their recommendations, however, refer to the whole range of language teaching including, for example, business and secretarial courses. The "pro-Russian" lobby maintains that the school timetable is now so overburdened that few scienceorientated students will be able to fit in a third optional language and will, accordingly, have no access to Russian scientific literature.

To the present generation of Finnish scientists, however, a lack of knowledge of Russian seems no particular burden. They use the cover-to-cover English-language translations of Soviet journals, and have little need, they say, for spoken Russian as a medium of scientific communication.

Vera Rich.

\section{Experimental animals}

\section{Lab invaded}

The UK Agricultural Research Council's Institute of Animal Physiology at Babraham, near Cambridge, has lived under threat of physical attack by antivivisectionists for several years. Last weekend the expected happened when a group of demonstrators forced their way into administrative buildings and laboratories housing animals. One object of the invasion was apparently to photograph animals in the laboratory.

The cost of the damage is small - no scientific experiments were tampered with. Preliminary estimates put it at a few hundred pounds. But, says the ARC statement, the noise of the break-in and the flashing bulbs of cameras must have caused alarm to the animals, which are accustomed to good treatment. this week, the ARC also said that neither "outsize" goats nor crossbreeds between goats and horses are kept at Babraham. Some demonstrators questioned on the site were apparently under the misapprehension that toxicity tests with cosmetics and cigarettes were being carried out.

The Institute of Animal Physiology has been a focus for the anti-vivisectionists for some time. The institute has pointed out before that all experiments done there are subject to licensing by the Home Office and are not exceptional in that similar experiments take place in other laboratories.

Judy Redfearn

\section{Whaling quotas}

\section{More wrangling}

The 1980 general meeting of the International Whaling Commission at Brighton on 21-26 July will have on its agenda a call for a total moratorium on whaling. This is the third time that the issue has been raised; on previous occasions, however (1972 and 1979), the motion was amended to one for selective moratoria. This year, the proposal for a total moratorium is tabled, inter alia, by France, the Netherlands and the United States, and is felt to have an even chance of success.

As in previous years, defeat or amendment of the motion would probably result not from a change of heart by the pro-moratorium lobby but from a feeling that adoption of such a motion would push anti-moratorium countries out of the convention and therefore beyond international control.

The way in which the argument at Brighton is likely to go can be told from what opponents of a total moratorium are saying in advance. One of the strongest opponents of a total moratorium, the Soviet Union, recently made its position
After some reports in the press earlier

clear in an English-language broadcast on Moscow radio. Calls for a total moratorium, said commentator Boris Belitskii, have no ecological basis, but are based on emotional attitudes encouraged in some quarters for political reasons.

The English-language broadcast added that in the case of really endangered species and in certain limited areas the Soviet Union has cut back its whaling considerably. (In the case of the baleen whales of the Sea of Okhotsk, a 2-year total ban has restored the population from the verge of extinction.) The broadcast went on to say that, over the past few years, the Soviet Union has closed down on-shore whaling factories and has disbanded the whaling fleet based on the Baltic port of Kaliningrad, dispersing the ships to marine and ichthyological research.

At present, Soviet whaling operation are said to be based on Vladivostok, and the two flotillas, with mother ships Sovetskaya Rossiya and Sovetskaya Ukraina, carry the necessary international observers as well as Soviet marine ecologists.

Rhetoric apart, the Soviet Union and other anti-moratorium countries such as Japan appear to have a certain case: they joined, they say, a "whaling" commission (to control and maintain the industry) not an "anti-whaling" commission.

There has been considerable speculation that, should the pro-moratorium advocates carry the day at Brighton, the Soviet Union and Japan might set up a rival commission of their own. Already the two countries have had some bilateral cooperation over quotas.

When, last year, the Soviet Union accepted the IWC's decision for a partial moratorium, in which fishing from factory ships would be confined to minke whales, it implemented this decision by ceding to Japan its North Pacific quota of 230 bryde whales in return for 300 of the less valuable minke whales from Japan's quota in the Antarctic.

Vera Rich

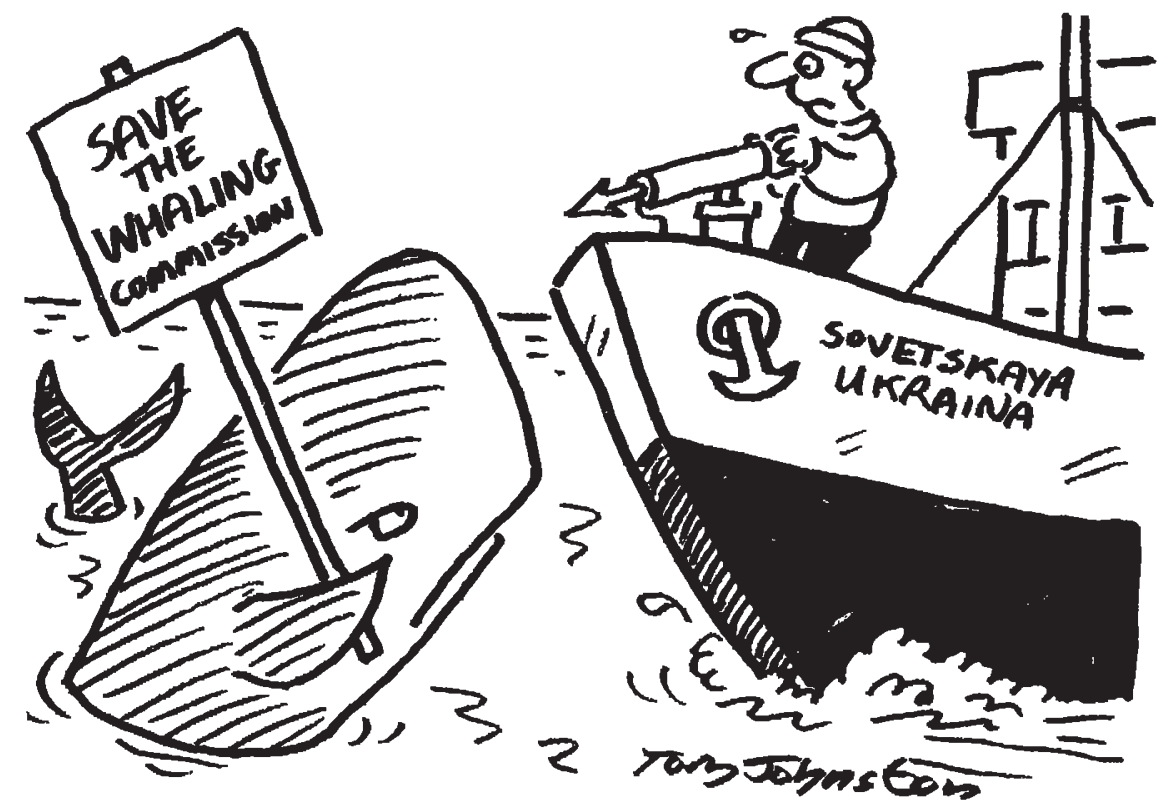

